\title{
Changes in column inventories of carbon and oxygen in the Atlantic Ocean
}

\author{
T. Tanhua ${ }^{1}$ and R. F. Keeling ${ }^{2}$ \\ ${ }^{1}$ Department of Marine Biogeochemistry, GEOMAR Helmholtz Centre for Ocean Research Kiel, Kiel, Germany \\ ${ }^{2}$ Geosciences Research Division, Scripps Institution of Oceanography, University of California San Diego, \\ La Jolla, CA, USA
}

Correspondence to: T. Tanhua (ttanhua@geomar.de)

Received: 15 June 2012 - Published in Biogeosciences Discuss.: 3 July 2012

Revised: 25 October 2012 - Accepted: 9 November 2012 - Published: 26 November 2012

\begin{abstract}
Increasing concentrations of dissolved inorganic carbon (DIC) in the interior ocean are expected as a direct consequence of increasing concentrations of $\mathrm{CO}_{2}$ in the atmosphere. This extra DIC is often referred to as anthropogenic carbon $\left(\mathrm{C}_{\mathrm{ant}}\right)$, and its inventory, or increase rate, in the interior ocean has previously been estimated by a multitude of observational approaches. Each of these methods is associated with hard to test assumptions since $\mathrm{C}_{\text {ant }}$ cannot be directly observed. Results from a simpler concept with fewer assumptions applied to the Atlantic Ocean are reported on here using two large data collections of carbon relevant bottle data. The change in column inventory on decadal time scales, i.e. the storage rate, of DIC, respiration compensated DIC and oxygen is calculated for the Atlantic Ocean. We report storage rates and the confidence intervals of the mean trend at the $95 \%$ level (CI), reflecting the mean trend but not considering potential biasing effects of the spatial and temporal sampling. For the whole Atlantic Ocean the mean trends for DIC and oxygen are non-zero at the $95 \%$ confidence level: DIC: 0.86 (CI: 0.72-1.00) and oxygen: -0.24 (CI: $-0.41-(-0.07)) \mathrm{mol} \mathrm{m}^{-2} \mathrm{yr}^{-1}$. For oxygen, the whole Atlantic trend is dominated by the subpolar North Atlantic, whereas for other regions the $\mathrm{O}_{2}$ trends are not significant. The storage rates are similar to changes found by other studies, although with large uncertainty. For the subpolar North Atlantic the storage rates show significant temporal and regional variation of all variables. This seems to be due to variations in the prevalence of subsurface water masses with different DIC and oxygen concentrations leading to sometimes different signs of storage rates for DIC compared to published $\mathrm{C}_{\text {ant }}$ estimates. This study suggest that accurate as-
\end{abstract}

sessment of the uptake of $\mathrm{CO}_{2}$ by the oceans will require accounting not only for processes that influence $\mathrm{C}_{\text {ant }}$ but also additional processes that modify $\mathrm{CO}_{2}$ storage.

\section{Introduction}

The ocean has stored a large fraction of the $\mathrm{CO}_{2}$ emitted by human activities over the last few hundred years, i.e. the anthropogenic $\mathrm{CO}_{2}\left(\mathrm{C}_{\mathrm{ant}}\right)$. A major scientific challenge today is to assess the oceanic sink and storage of $\mathrm{CO}_{2}$. It is therefore relevant to monitor the storage rate of dissolved inorganic carbon (DIC) in the ocean and to assess its sensitivity to (climate-induced) changes in circulation and biology. Much of prior work has focused on determining the total oceanic uptake of $\mathrm{CO}_{2}$ in the ocean due to increasing atmospheric $\mathrm{CO}_{2}$ concentrations, i.e. changes related to the thermodynamic air-sea disequilibrium driven by atmospheric changes (i.e. $\left.\mathrm{C}_{\text {ant }}\right)$. Changes in oceanic $\mathrm{CO}_{2}$ content due to changes in the ocean carbon cycle driven by other internal ocean factors that impact air-sea exchange of $\mathrm{CO}_{2}$, such as changes in circulation or productivity/respiration, are most often not considered. Over long time scales and over large areas, the $\mathrm{C}_{\mathrm{ant}}$ component has so far been dominating over the changes in DIC due to increase in the concentration of $\mathrm{C}_{\mathrm{ant}}$, although on smaller spatial and temporal scales the natural variability can dominate.

Decadal storage rates of ocean dissolved inorganic carbon (DIC) can be assessed by comparing direct measurements of the carbonate system and related variables obtained from the same stations or along the same section; this is often referred 
to as "repeat hydrography". It has been shown that the storage rates calculated from repeat hydrography can be scaled to encompass the full $\mathrm{C}_{\text {ant }}$ inventory in the North Atlantic by assuming steady state circulation and transient steady state behavior of the anthropogenic carbon (e.g. Tanhua et al., 2007; Gammon et al., 1982), and that the $\mathrm{C}_{\mathrm{ant}}$ concentration in the surface ocean is, to a first approximation, exponentially increasing. In principle, the change in DIC concentration between repeat measurements (i.e. $\triangle D I C$ ) at a specific location and depth in the ocean can be assumed to represent the anthropogenic component, which can be integrated over the water column to assess the storage rate of anthropogenic carbon. However, a direct comparison of the DIC fields usually show large variability, i.e. a patchy image, of the decadal change in DIC (or any other property) concentrations due to spatial and temporal variability in the ocean such as eddies and variable location of ocean fronts (e.g. Wanninkhof et al., 2010).

A common approach to estimate $\mathrm{C}_{\mathrm{ant}}$ involves combining DIC data with dissolved $\mathrm{O}_{2}$ or nutrient data to reduce variability due to internal ocean processes such as changes in remineralization. The variable effect on DIC is assumed to be captured from other tracers assuming fixed elemental ratios (C/N, C/P, C/O, i.e. Redfield ratios). A related approach uses multiple linear regressions (MLRs) where relations between a number of relevant properties, such as nutrients, oxygen and salinity are used to determine the DIC concentration of the sample. The use of MLR has the capacity to compensate for some of the small scale variability in the ocean and the result is usually relatively smooth fields of $\triangle$ DIC. A variation of the MLR method was suggested by Friis et al. (2005) in which the MLR coefficients for both the cruise are subtracted from each other and then directly used for the calculation of the $\triangle \mathrm{DIC}$. This approach is known as extended MRL (eMLR). Wanninkhof et al. (2010) finds significant biases and various amount of scatter in the $\triangle$ DIC fields depending on the method applied to a section through the Atlantic Ocean, indicating that the correct choice of methodology is critical. A thorough analysis of potential biases in the MLR method is provided by Levine et al. (2008), where particularly potential biases in the deep water formation regions were pointed out.

Furthermore, estimates of $\mathrm{C}_{\text {ant }}$ that use $\mathrm{O}_{2}$ as a component of tracer combination are subject to an easily understood bias. The integration of the tracer combination over the column to yield the change in the inventory of $\mathrm{C}_{\text {ant }}$ yields a sum of terms, one for inventory of each of the components, including the $\mathrm{O}_{2}$ inventory. Globally, the change in $\mathrm{O}_{2}$ inventory, however, is largely controlled by air-sea exchanges of $\mathrm{O}_{2}$ (Keeling and Garcia, 2002). Thus a combined tracer that includes $\mathrm{O}_{2}$ will be sensitive not just to processes driving long-term uptake of $\mathrm{CO}_{2}$ by the oceans, but also processes driving long-term changes in $\mathrm{O}_{2}$ (Keeling, 2005; Yool et al., 2010). Recent studies suggest that the change in global ocean $\mathrm{O}_{2}$ inventory is decreasing at the level of $\sim 50 \mathrm{Tmol} \mathrm{yr}^{-1}$ due to warming and increased ocean stratification (Keeling et al., 2010; Helm et al., 2011), which is significant compared to estimated global ocean $\mathrm{CO}_{2}$ uptake of $\sim 200 \mathrm{Tmol} \mathrm{yr}^{-1}$. A tracer combination that uses $\mathrm{O}_{2}$ therefore cannot yield a reliable estimate of ocean $\mathrm{CO}_{2}$ uptake unless it is combined with independent estimates of the changes in ocean $\mathrm{O}_{2}$ inventory (Keeling et al., 2010). Estimates of $\mathrm{C}_{\text {ant }}$ that include potential temperature as a correlating variable will be similarly sensitive to changes in ocean heat content (Levitus et al., 2012).

Related problems have been documented locally. For instance, time series data from the DYFAMED site in the Western Mediterranean Sea show increasing DIC concentrations with time for almost all depths (Touratier and Goyet, 2009), but the authors conclude that the $\mathrm{C}_{\mathrm{ant}}$ concentration is decreasing based on a particular method to calculate the $\mathrm{C}_{\mathrm{ant}}$ concentration. Similarly, Wakita et al. (2010) present measured DIC concentrations on a time-series station from the NW Pacific Ocean (stations KNOT and K2), and conclude that the $\mathrm{C}_{\mathrm{ant}}$ concentration has a significant increasing trend with time although the DIC concentrations do not show such a trend. The reason for this discrepancy is often changes in circulation, i.e. another water mass with different preformed concentrations, ventilation etc. becomes more dominate at a certain location, or the thicknesses of the water mass at one location are varying with time. Other reasons might be changes to any one of the following processes, or a combination thereof: remineralization-depth, biological production, oxygen concentrations (Keeling et al., 2010), Redfield ratios (Riebesell et al., 2007), dominating phytoplankton species (Cermeno et al., 2008), or stratification. A review of some important such "secondary" mechanisms are discussed in Sabine and Tanhua (2010). The conclusions of Tourtatier and Goyet (2009) and Wakita et al. (2010), for instance, demonstrate that the DIC inventory of a water parcel do not necessary follow the trend in the inventory of $\mathrm{C}_{\text {ant }}$.

Methods to determine $\mathrm{C}_{\text {ant }}$ uptake, whether from transient tracers or decadal budgets, also suffer from an additional fundamental limitation. If the ocean circulation is not steady, or other changes in biogeochemical cycling are occurring, then even a perfect determination of $\mathrm{C}_{\text {ant }}$ (assuming measurement limitations could be overcome), is not sufficient because $\mathrm{C}_{\text {ant }}$ is then no longer a complete measure of the uptake of $\mathrm{CO}_{2}$ by the oceans. Additional contributions to the air-sea exchange of $\mathrm{CO}_{2}$ due to non-steady biology or ocean circulation also need to be quantified. It is fundamentally a matter of the question being asked: Are we primarily interested in the change of $\mathrm{C}_{\mathrm{ant}}$ with time, i.e. the excess $\mathrm{CO}_{2}$ in the ocean that is a direct consequence of increasing atmospheric $\mathrm{CO}_{2}$ concentrations, or are we interested to know the actual change of the inorganic carbon pool in the ocean due all processes? If the goal is to quantify the impact of the ocean on the global trend in atmospheric $\mathrm{CO}_{2}$, then the answer is clear: all processes contributing to air-sea exchange must be accounted for. To achieve this goal, it is therefore not sufficient simply to improve methods for determining $\mathrm{C}_{\text {ant }}$. What is needed is 
a method that can determine the ocean $\mathrm{CO}_{2}$ uptake from all processes.

Conceptually, there is actually a simple method available for determining the total uptake of $\mathrm{CO}_{2}$ by the oceans. One simply measures DIC with sufficient accuracy and coverage to establish the total inventory of DIC in the global ocean, and then one tracks this over time through repeat hydrography. Although the DIC inventory can vary due to several processes, including any imbalance globally in the production of destruction of organic carbon, or in the global rate of the precipitation or dissolution of calcium carbonate, these processes are currently dwarfed globally by the changes caused by uptake of $\mathrm{CO}_{2}$ from the atmosphere. A measurement of changes in the DIC inventory, with small corrections applied to account for organic carbon or carbonate effects (e.g. based on alkalinity or dissolved organic carbon measurements), would effectively determine the $\mathrm{CO}_{2}$ uptake by all processes.

The principle difficulty with this method is that it requires detecting trends in the inventory of DIC against the background variability, not by using correlating tracers, but simply by having sufficiently high coverage. We are not aware of any attempt to date to apply this method. Over the past few decades, however, a large increase in the coverage of DIC measurements has been realized in certain ocean regions. As a first step, we focus here on the feasibility of tracking changes in the DIC column inventory of the upper $2000 \mathrm{~m}$ of the water column in the Atlantic Ocean over the past few decades. Our study takes advantage of major new data assets including the GLODAP (Key et al., 2004) and CARINA (Key et al., 2010) data collections, which together provide an unprecedented coverage in time and space. Our study explores not just the changes in DIC inventory, but also changes in dissolved $\mathrm{O}_{2}$, and in a combination of dissolved $\mathrm{O}_{2}$ and DIC that compensates for changes due to photosynthesis and respiration, which we call abiological DIC, or $\mathrm{DIC}_{\text {abio. }}$. Changes in dissolved $\mathrm{O}_{2}$ are of interest in relation to recent studies suggesting that $\mathrm{O}_{2}$ levels in the ocean may be declining due to increasing ocean stratification, and $\mathrm{DIC}_{\text {abio }}$ is of interest because of its potential close relationship to $\mathrm{C}_{\text {ant }}$.

The change in DIC column inventory is a function of the air-sea flux, the convergence or divergence of DIC, the net change in organic carbon in the water column, and the net formation or dissolution of carbonate. Similarly, the change in oxygen column inventory is a function of the air-sea flux, convergence or divergence of oxygen, and the net change in organic carbon in the water column. The convergence and divergence terms will, obviously, become less important the larger the scale. In this study we focus on relating observed changes in column inventory of DIC and oxygen to the airsea flux component and the convergence/divergence terms of these relations. We are assuming no change in organic carbon concentrations and $\mathrm{CaCO}_{3}$ since these are presumably negligible and we are not aware of any observational evidence for the contrary.

\section{Methods}

\subsection{Data}

This study uses data contained in the data products for the Atlantic Ocean within GLODAP (Global Ocean Data Analysis Project, http://cdiac.ornl.gov/oceans/glodap/index.html; Key et al., 2004) and CARINA (CARbon IN the Atlantic, http://cdiac.ornl.gov/oceans/CARINA; Key et al., 2010).

These products contain carbon relevant data from 48 and 98 cruises for the Atlantic Ocean, respectively. Both data products have gone through rigorous quality control procedures to assure the highest possible quality and internal consistency (e.g. Stendardo et al., 2009; Pierrot et al., 2010). Together these data collections form the most comprehensive and consistent data set for carbon related water properties ever gathered for the ocean to date. The combination of these products is suitable for assessments of oceanic carbon inventories and uptake rates. However, there are a few known deficits to the GLODAP data, and a few duplications with CARINA. Thus the GLODAP data were modified in the following manner: (1) Cruise 45 (TTONAS_1-7) DIC and Alkalinity data are adjusted accordingly to Tanhua and Wallace (2005). (2) Cruise 23 (OACES93) was overcorrected for oxygen in GLODAP; therefore, oxygen is adjusted by $-7.5 \mathrm{umol} \mathrm{kg}{ }^{-1}$ as suggested by Sabine et al. (2005). (3) Cruise 24 (3230CHITHER2_1-2) is adjusted for alkalinity by $-8 \mathrm{umol} \mathrm{kg}^{-1}$ (Velo et al., 2009). (4) GLODAP cruises 2,3 , and 29 are also available in both data collections, but with additional data in CARINA. To avoid using the same cruise twice, duplicate cruises are excluded from the GLODAP Atlantic data. Furthermore, we did not use any of the GEOSECS data in our calculation because of the large and variable biases in DIC for this data set, up to $27 \mathrm{umol} \mathrm{kg}^{-1}$ (e.g. Peng and Wanninkhof, 2010).

The property AOU (apparent oxygen utilization) is calculated as the difference between measured oxygen concentration and the calculated saturation of oxygen at the temperature and salinity of the sample using the solubility of Weiss (1970). We use AOU to separate changes in oxygen concentration due to change in heat content or salinity (changes that will change the equilibrium concentration of oxygen) from changes due to ventilation/circulation or respiration. Furthermore, AOU is less sensitive to seasonal variations than dissolved $\mathrm{O}_{2}$ because it compensates for seasonality in mixed layer temperature, and non-linearity issues in the oxygen solubility is less of an issue if AOU is used. The property $\mathrm{DIC}_{\mathrm{abio}}$ refers to dissolved inorganic carbon that has been corrected for dissolution of organic matter according to

$\mathrm{DIC}_{\mathrm{abio}}=\mathrm{DIC}-0.69 \times$ AOU .

The factor 0.69 is the ratio $\mathrm{C} /-\mathrm{O}_{2}$ for remineralization of organic matter as suggested by Anderson and Sarmiento (1994). The relation in Eq. (1) neglects the effects of dissolution/formation of calcium carbonate, i.e. changes in 
alkalinity, assuming that changes in alkalinity over the short time periods in question are negligible. The storage rate of $\mathrm{DIC}_{\mathrm{abio}}$ thus reflect changes in DIC not due to respiration of organic matter, and thus may better reflect changes in $\mathrm{C}_{\mathrm{ant}}$ than the storage rate of DIC does. Different choices for calculating $\mathrm{DIC}_{\mathrm{abio}}$ are possible, potentially the most promising would be the use of phosphate since this nutrient is conserved in the ocean (e.g. Sabine et al., 1999). However, the low dynamically range of phosphate (phosphate is roughly 170 times less sensitive to remineralization than oxygen is (Anderson and Sarmiento, 1994)), the lower accuracy, and the lower frequency of phosphate measurements vs. oxygen measurements (e.g. Tanhua et al., 2010) makes this choice less attractive for observational studies.

In a study where the contribution of anthropogenic carbon was considered, Körtzinger et al. (2001) found a slightly higher ratio (0.75). This is similar to the factor " $a$ " in the TrOCA method (0.78) found by Touratier et al. (2007) that also considers mineralization of organic matter in the alkalinity budget. The uncertainty in the $\mathrm{C} /-\mathrm{O}_{2}$ ratio introduces uncertainty in the calculation of $\Delta \mathrm{DIC}_{\mathrm{abio}}$, particularly for areas where we find large storage rates of AOU, see Sect. 3.1.

\subsection{Storage rate calculations}

As the first step in the analysis, stations with measurements of DIC and oxygen from the surface to at least $2000 \mathrm{~m}$ depth with sufficient vertical resolution to allow for reasonable interpolation the data were identified in the combined CARINA/GLODAP data collections. For these stations we vertically interpolated the data using a piecewise hermite interpolating polynomial routine. The maximum vertical distance over which interpolation was allowed was $65 \mathrm{~m}$ in the top $100 \mathrm{~m}, 205 \mathrm{~m}$ between 90 and $300 \mathrm{~m}$ depth, $405 \mathrm{~m}$ between 300 and $750 \mathrm{~m}$ depth, $505 \mathrm{~m}$ between 750 and $1500 \mathrm{~m}$ depth, and $705 \mathrm{~m}$ below $1500 \mathrm{~m}$ depth. If the distance between two samples exceeds these definitions, the column inventory was not calculated. These limits represent a delicate balance between a rigorous definition that tend to exclude a large fraction of the stations due to too sparse vertical sampling and a too generous definition that risk creating bad interpolation values in sharp gradients, thus biasing the column inventory estimate. The column inventory was calculated by integrating the interpolated concentration profile from the surface down to $2000 \mathrm{~m}$ depth for DIC, DIC $a$ abio, oxygen and AOU for each one of the stations. At this stage we converted the gravimetric units reported in CARINA/GLODAP to volumetric units so that:

column inventory $=\int_{0}^{2000} C \times \operatorname{rhod} z$

where $C$ is the vertically interpolated concentration in gravimetric units, and rho is the density at in situ $T, P$. We then located stations sampled within $100 \mathrm{~km}$ of each other and calculated the difference between the column inventories of the stations in the pair. There are inherent uncertainties in calculating column inventories (see Sect. 2.3); however, the scatter in storage rate for station pairs decreases with time between the repeats, i.e. the signal to noise ratio improves with increasing time between repeats. We found that a minimum time between repeats of a station of $6 \mathrm{yr}$ was a reasonable minimum time for this study. With the combined CARINA/GLODAP data set, 1204 station pairs in the Atlantic Ocean qualify for being repeat stations. If we increase the maximum allowed distance between stations to $200 \mathrm{~km}$, we find 6757 station pairs but with significant more noise in the result, i.e. $200 \mathrm{~km}$ distance is generally too large for considering them being a repeat station. The storage rate was calculated as the difference in column inventory of a station pair divided by the time in years between the repeats of this station so that the unit of storage rate is $\mathrm{mol} \mathrm{m}^{-2} \mathrm{yr}^{-1}$.

For most regions there are only small changes in the property fields below $2000 \mathrm{~m}$ depth on decadal time-scales, thus analytical uncertainties and data-biases tend to the dominate signal merely introducing noise in the data with little additional contribution. In addition, by always calculating the storage rate over $2000 \mathrm{~m}$ water column, the different stations pairs can easily be compared to each other. Changes in DIC and oxygen below $2000 \mathrm{~m}$ depth were therefore neglected. Another issue is changes in column inventories due to changes in season, i.e. one could expect the column inventory of oxygen and DIC should be different in summer than in winter, everything else being constant. Thus, if the repeat stations are occupied during different seasons, the storage rate calculation might be affected. In order to investigate the effect of sampling during different seasons we conducted one analysis based on the number of months difference in the sampling for the station pair, and one analysis where the top $200 \mathrm{~m}$ of the water column, (assuming that this is where the seasonal signal can be detected) was excluded. Sampling during different time of the year has only a small, and mostly insignificant, effect of the storage rate calculation. This seems to be mainly due to the surface mixed layer affected by seasonality being relatively small in comparison to the $2000 \mathrm{~m}$ of water column we are analyzing, and that the seasonal changes are relatively small. All station pairs were included in the analysis independent of the time of year the stations were sampled, realizing that this could potentially bias the analysis or at least increase the scatter in the data, but with the benefit of having significantly more data available for the analysis. A filter was applied to the storage rates in order to remove outliers (see Sect. 2.3), i.e. storage rate estimates more than 5 standard deviations from the mean of all storage rates were removed from the analysis, assuming that those suffered from interpolation errors, biased measurements or some other problem. Figure 1 shows the time span of the station pairs that we have used for this study; for areas in the North Atlantic we have also calculated the storage rates for different time periods, see Sect. 3.3. 

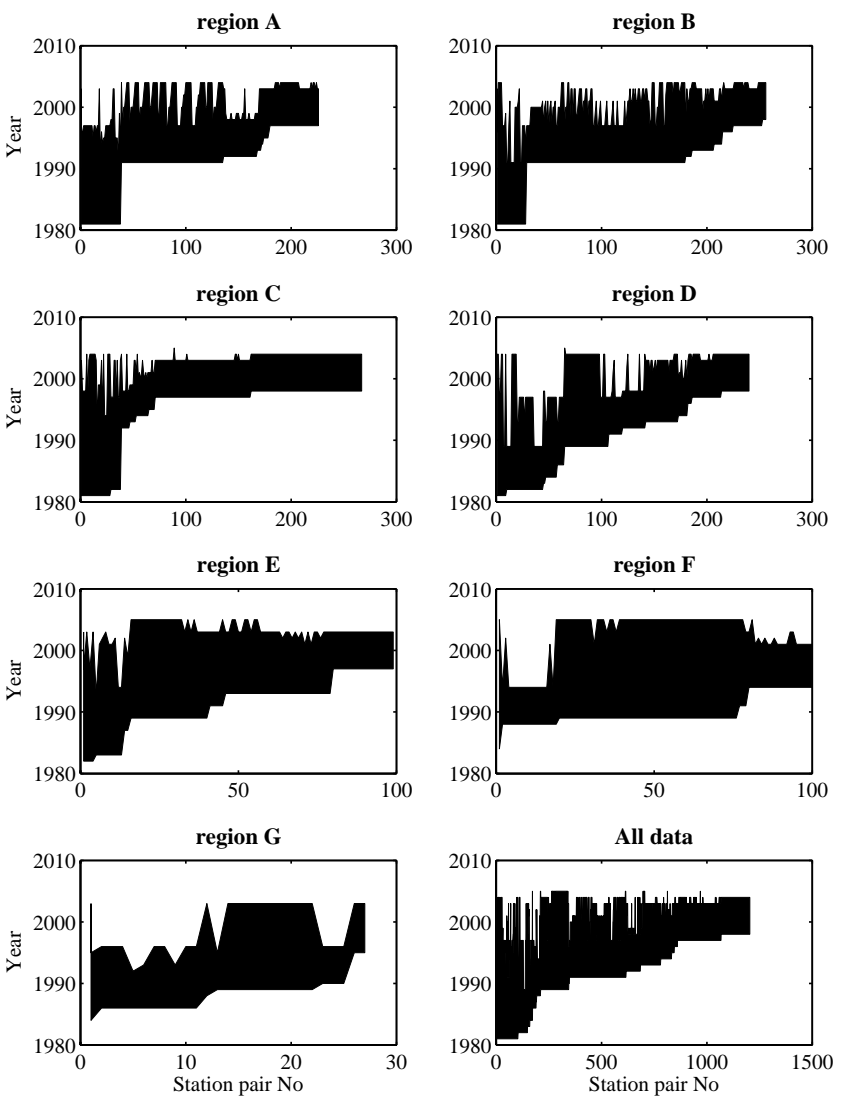

Fig. 1. Distribution of the time span for which the various station pairs were sampled. The different panels shows the different geographical areas (see Fig. 2). The time between the first and second repeat of a station are filled in, sorted by the time of the first cruise.

The Atlantic Ocean was divided into 7 areas in order to resolve differences in the storage rate for different areas: (a) the western basin of the subpolar North Atlantic, (b) the eastern basin of the subpolar North Atlantic, (c) the western basin in the subtropical North Atlantic, (d) the eastern basin of the subtropical North Atlantic, (e) the tropical Atlantic between $15^{\circ} \mathrm{N} / \mathrm{S}$, (f) the western basin of the South Atlantic, and (g) the eastern basin of the South Atlantic (e.g. Fig. 2). No distinction was made between subpolar and subtropical South Atlantic due to limited number of data in the South Atlantic, but due regional differences in storage rates we sub-divided regions A and B into a northern and southern part. The station pairs that we have used for the calculation of storage rates are unevenly distributed through the regions, potentially causing spatial bias in estimates of average storage rates. In order to reduce the biasing effects, we divided the Atlantic in $2^{\circ} \times 2^{\circ}$ bins (separated by odd latitudes and even longitudes), calculated the arithmetic mean of the storage rates in each bin, and finally averaged the bins in order to calculate the average storage rate for the regions. The mean storage rates for each bin were used to calculate the $95 \%$ confidence interval (CI) of the mean (Table 1). Bins with no data were not included in the calculation of average storage rates or confidence intervals, i.e. we did not attempt to interpolate our data to cover areas without any data, see Sect. 2.3 for a discussion on potential biases.

\subsection{Sources of uncertainties}

We now consider several sources of uncertainty in the storage rate estimates related to either: (1) the calculation of storage rates for a station pair, or (2) for calculating average storage rates (and their uncertainty) for a region; these will be discussed separately below.

\subsubsection{Uncertainty in storage rate for a station pair}

One source of random uncertainty is related to sharp vertical gradients of properties in the ocean. These are typically found in the upper ocean and the gradients tend to be more pronounced at low latitudes than in high latitudes. For instance, the concentration of DIC or oxygen can change by $50-100 \mu \mathrm{mol} \mathrm{kg}^{-1}$ within less than $100 \mathrm{~m}$ depth. The interpolation of bottle measurements over such gradients is sensitive to the vertical distance between the measurements and the steepness of the gradient, see discussion in Sect. 2.2. Similarly, internal waves in the ocean are abundant in the ocean and frequently move the gradient of properties up or down with tens of meters, often within hours or days. Thus, depending on the timing of the particularly station, internal wave action will produce random noise in the column inventory. The magnitude of these uncertainties are difficult to assess, but a "worst case scenario" where the gradient is miss-interpolated (or moved up/down by internal wave action) over a $40 \mathrm{~m}$ interval to yield a bias of $50 \mu \mathrm{mol} \mathrm{\textrm {kg } ^ { - 1 }}$ would result in a $2 \mathrm{~mol} \mathrm{~m}^{-2}$ bias in the column inventory (i.e. $0.2 \mathrm{~mol} \mathrm{~m}^{-2} \mathrm{yr}^{-1}$ for cruises $10 \mathrm{yr}$ apart). Another source of uncertainty in the column inventories are biases and random errors in the measurements. The originators of the internally consistent data collections used in this study (GLODAP and CARINA) have attempted to remove any systematic bias in the measurements. There is however a "limit of making an adjustment to the original data" that is $4 \mu \mathrm{mol} \mathrm{kg}^{-1}$ for DIC and $1 \%$ for oxygen (e.g. Tanhua et al., 2010). A "worst case scenario" would be if the two cruises in a station pair are both biased in different directions. For example, if the property values are biased by $3 \mu \mathrm{mol} \mathrm{kg}{ }^{-1}$ for both cruises (in different directions) over the whole $2000 \mathrm{~m}$ of water column, this would result in a bias in the inventory change of $12 \mathrm{~mol} \mathrm{~m}^{-2}$. Random errors in the same range (i.e. $4 \mu \mathrm{mol} \mathrm{kg}{ }^{-1}$ for DIC and $1 \%$ for oxygen) due to analytical uncertainties can be expected. In the deep water column where gradients are small, the vertical distances between samples are typically more than $100 \mathrm{~m}$. If, for instance, one measurement is off by $6 \mu \mathrm{mol} \mathrm{kg}-1$ and this influences the interpolation over $200 \mathrm{~m}$, it translates to a bias in the column inventory of about 
Table 1. Averaged storage rates of DIC, DIC ${ }_{\mathrm{abio}}$, Oxygen and AOU for the 7 regions (see Figs. 2-5) and for the whole Atlantic as described in the text. The top row of each cell gives the average storage rates of the $2^{\circ} \times 2^{\circ}$ bins within each region; the bottom line in each cell gives the $95 \%$ confidence interval. The number of samples (i.e. station pairs, $N$ ) for each area is indicated in the left column.

\begin{tabular}{|c|c|c|c|c|}
\hline Region & $\begin{array}{r}\text { DIC } \\
\mathrm{mol} \mathrm{m}^{-2} \mathrm{yr}^{-1}\end{array}$ & $\begin{array}{r}\mathrm{DIC}_{\mathrm{abio}} \\
\mathrm{mol} \mathrm{m}^{-2} \mathrm{yr}^{-1}\end{array}$ & $\begin{array}{r}\text { Oxygen } \\
\mathrm{mol} \mathrm{m}^{-2} \mathrm{yr}^{-1}\end{array}$ & $\mathrm{~mol} \mathrm{~m}^{-2} \mathrm{yr}^{-1}$ \\
\hline $\mathrm{A}$ - subpolar NW & 0.97 & 0.63 & -0.80 & 0.49 \\
\hline$N=226$ & $0.62-1.31$ & $0.15-1.12$ & $-1.36-(-0.23)$ & $0.13-0.85$ \\
\hline A - north & 0.57 & -0.07 & -1.67 & 0.96 \\
\hline$N=201$ & $0.15-0.99$ & $-0.58-0.43$ & $-2.20-(-1.15)$ & $0.56-1.35$ \\
\hline A - south & 1.43 & 1.47 & 0.12 & -0.05 \\
\hline$N=25$ & $0.95-1.91$ & $0.89-2.05$ & $-0.46-0.91$ & $-0.57-0.45$ \\
\hline B - subpolar NE & 0.91 & 0.40 & -0.94 & 0.78 \\
\hline$N=256$ & $0.63-1.19$ & $0.06-0.73$ & $-1.39-(-0.48)$ & $0.45-1.12$ \\
\hline B - North & 0.44 & -0.42 & -1.96 & 1.29 \\
\hline$N=166$ & $-0.04-0.92$ & $-0.84-0.00$ & $-2.61-(-1.31)$ & $0.73-1.85$ \\
\hline B - South & 1.12 & 0.77 & -0.47 & 0.56 \\
\hline$N=90$ & $0.80-1.45$ & $0.42-1.11$ & $-0.96-0.01$ & $0.15-0.97$ \\
\hline $\mathrm{C}$ - subtropical NW & 0.91 & 0.77 & -0.12 & 0.19 \\
\hline$N=267$ & $0.63-1.20$ & $0.46-1.08$ & $-0.63-0.39$ & $-0.15-0.53$ \\
\hline D - subtropical NE & 0.89 & 0.79 & -0.08 & 0.07 \\
\hline$N=240$ & $0.66-1.12$ & $0.54-1.04$ & $-0.37-0.22$ & $-0.26-0.39$ \\
\hline E - tropics & 0.35 & 0.56 & 0.30 & -0.28 \\
\hline$N=99$ & $0.00-0.69$ & $0.23-0.88$ & $-0.08-0.68$ & $-0.66-0.10$ \\
\hline F - SW Atlantic & 0.30 & 0.32 & 0.00 & -0.02 \\
\hline$N=100$ & $-0.20-0.80$ & $-0.07-0.70$ & $-0.28-0.28$ & $-0.36-0.32$ \\
\hline G - SE Atlantic & 1.98 & 2.04 & -0.32 & 0.01 \\
\hline$N=27$ & $1.38-2.60$ & $1.47-2.61$ & $-0.70-0.06$ & $-0.30-0.33$ \\
\hline The whole Atlantic & 0.86 & 0.73 & -0.24 & 0.18 \\
\hline$N=1204$ & $0.72-1.00$ & $0.59-0.87$ & $-0.41-(-0.07)$ & $0.04-0.32$ \\
\hline
\end{tabular}

$0.8 \mathrm{~mol} \mathrm{~m}^{-2}$ (assuming the samples above and below are accurate).

\subsubsection{Uncertainty in the storage rate for a region}

In this study, we are comparing pointwise changes in column inventories which means that we are sensitive to ocean variability such as eddies, shifts in fronts and water masses in our analysis. If these shifts are happening on short time scales they can bias the analysis, but if they are more permanent shifts in water mass distribution, etc. they represent changes that we do want to explore in this study. Our approach involves two-point comparisons at many locations and for many different time intervals, and thereby involves both temporal and spatial averaging. In fact, one difficulty in presenting the storage rates is that the station pairs cover both different time spans and regions. The confidence intervals presented in this study are based solely on the storage rates for $2^{\circ} \times 2^{\circ}$ bins that have been sampled. However, large areas of the Atlantic Ocean do not have any data (e.g. Fig. 2) so that there is a distinct possibility that our average values are biased in either direction. The samples are clearly not randomly distributed (both in time and space), making it difficult to assign rigorous confidence limits. The magnitude of these potential biases is difficult to assess, but it is safe to assume that the confidence intervals we present are lower limits. Figures 2-6 and 11 present the storage rates for all station pairs and illustrate the spatial and temporal variability in storage rates.

\section{Results}

It is interesting to note that from the more than 14000 stations available for the Atlantic Ocean in the CARINA/GLODAP data collection only results in $\sim 1200$ station pairs. Apart from stations being too far apart from each other, a large fraction of the stations do not have sufficient 

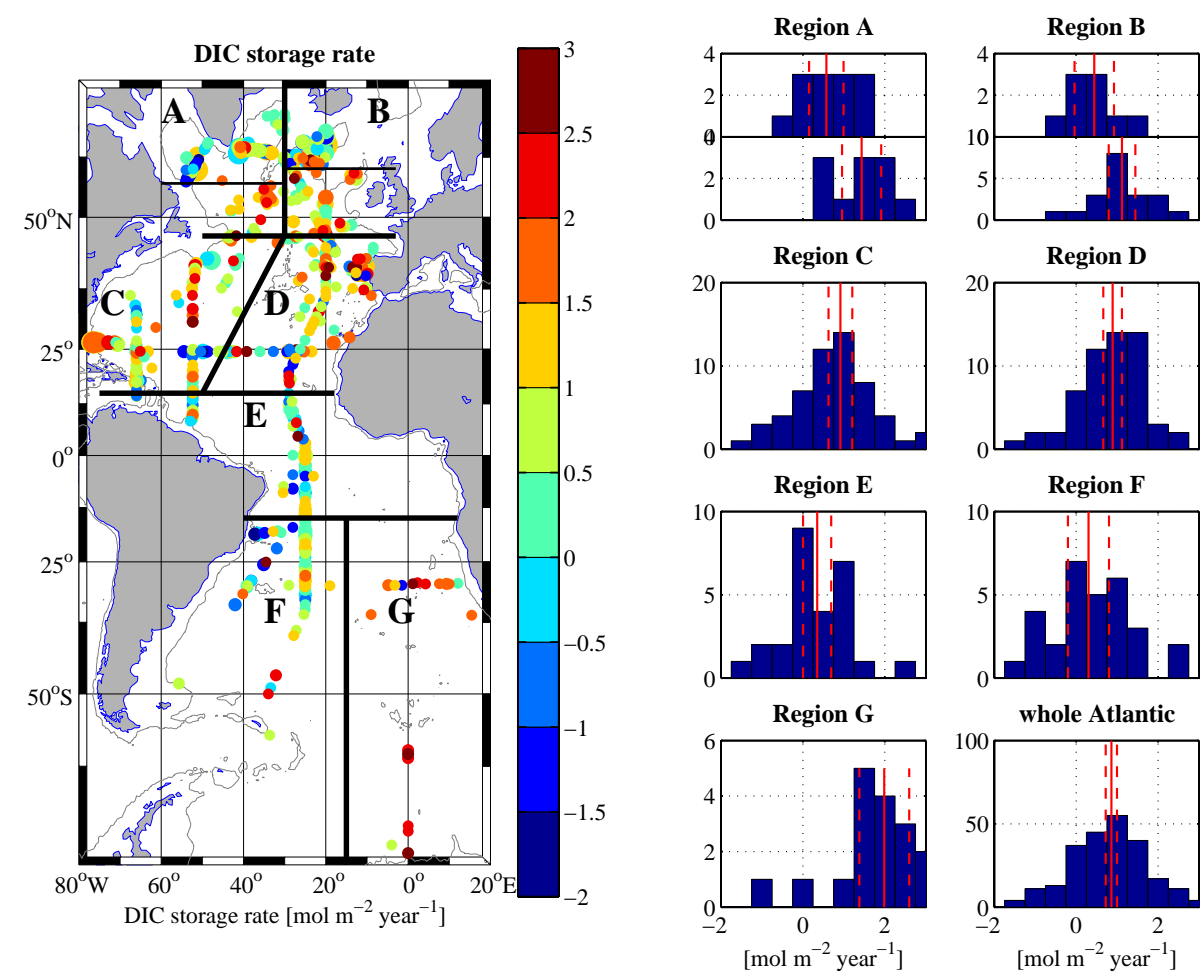

Fig. 2. Change in column inventory between two repeats of the same position, i.e. the storage rate (mol m${ }^{-2} \mathrm{yr}^{-1}$ ) for DIC in the Atlantic Ocean. Left side panel: the average of storage rates for each location is shown with the color-coded marker; the sizes of the markers are made proportionally larger depending on the number of repeats at each position. The $2000 \mathrm{~m}$ isobath is marked with a gray thin line. Right hand panels: histograms of the distribution of storage rates in $2^{\circ} \times 2^{\circ}$ bins (see text) for the 7 regions and for the sum of all the regions; note that for regions A and B, we show the southern (lower panel) and northern (upper panel) sub-regions separately (thin black lines on the map). The average value and the $95 \%$ confidence intervals are marked with red vertical lines.

vertical resolution to make meaningful vertical interpolation of the profiles. The insufficient vertical resolution for several of the profiles (particularly in the upper ocean) will most likely also affect attempts to interpolate any property over the entire basin for calculating inventories of, for instance, anthropogenic carbon. The storage rates and CIs for all regions and variables are listed in Table 1 and graphical representations of the spatial distribution of storage rates are shown in Figs. 2-5. In these figures all data that pass the criteria for a valid repeat measurement mentioned above are plotted; bluish colors for decreasing and green or reddish colors for increasing column inventories. Figure 6 represent the condensed information from Figs. 2-5, also listed in Table 1. A different view of the distribution of the storage rates is provided by the histograms in the right hand panel of Figs. 2-5, where the $95 \%$ confidence interval and the mean are indicated with vertical red lines.

It is evident from the maps in Figs. 2-5 that a bipolar distribution, i.e. non-Gaussian, of storage rates is present in several regions. Particularly, the northern parts of regions A and $B$ in the SPNA (i.e. the Irminger, Labrador, and northern Iceland Seas) are different from the southern parts of those regions. This is reflecting regional differences in storage rates, and will be discussed in more detail below. We are therefore presenting the average storage rates and confidence intervals for the northern and southern parts of regions A and B separately.

\subsection{DIC and DIC abio storage rates}

Changes in the column inventory per year, i.e. the storage rate, of DIC and $\mathrm{DIC}_{\mathrm{abio}}$ for the Atlantic Ocean, are viewed in Figs. 2 and 3 and are listed in Table 1. The mean DIC and $\mathrm{DIC}_{\mathrm{abio}}$ storage rates for the whole Atlantic are positive so that, as expected, there is an increase in the column inventory of DIC with time. For the whole Atlantic, the average storage rates for DIC and $\mathrm{DIC}_{\mathrm{abio}}$ are 0.86 (CI: 0.72-1.00) and 0.73 CI: $(0.59-0.87) \mathrm{mol} \mathrm{m}^{-2} \mathrm{yr}^{-1}$, respectively. The $95 \%$ confidence interval of the mean DIC and DIC $a$ abio storage rates indicates a positive storage rate in all regions, except region $\mathrm{F}$, the southwest Atlantic, and the northern portions of regions $\mathrm{A}$ and $\mathrm{B}$. The DIC average storage rate is around $0.9 \mathrm{~mol} \mathrm{~m}^{-2} \mathrm{yr}^{-1}$ for the North Atlantic (regions A to D), although with regional differences, and somewhat lower for the tropical and southwest Atlantic, whereas the southeast Atlantic shows a large increase in DIC. 

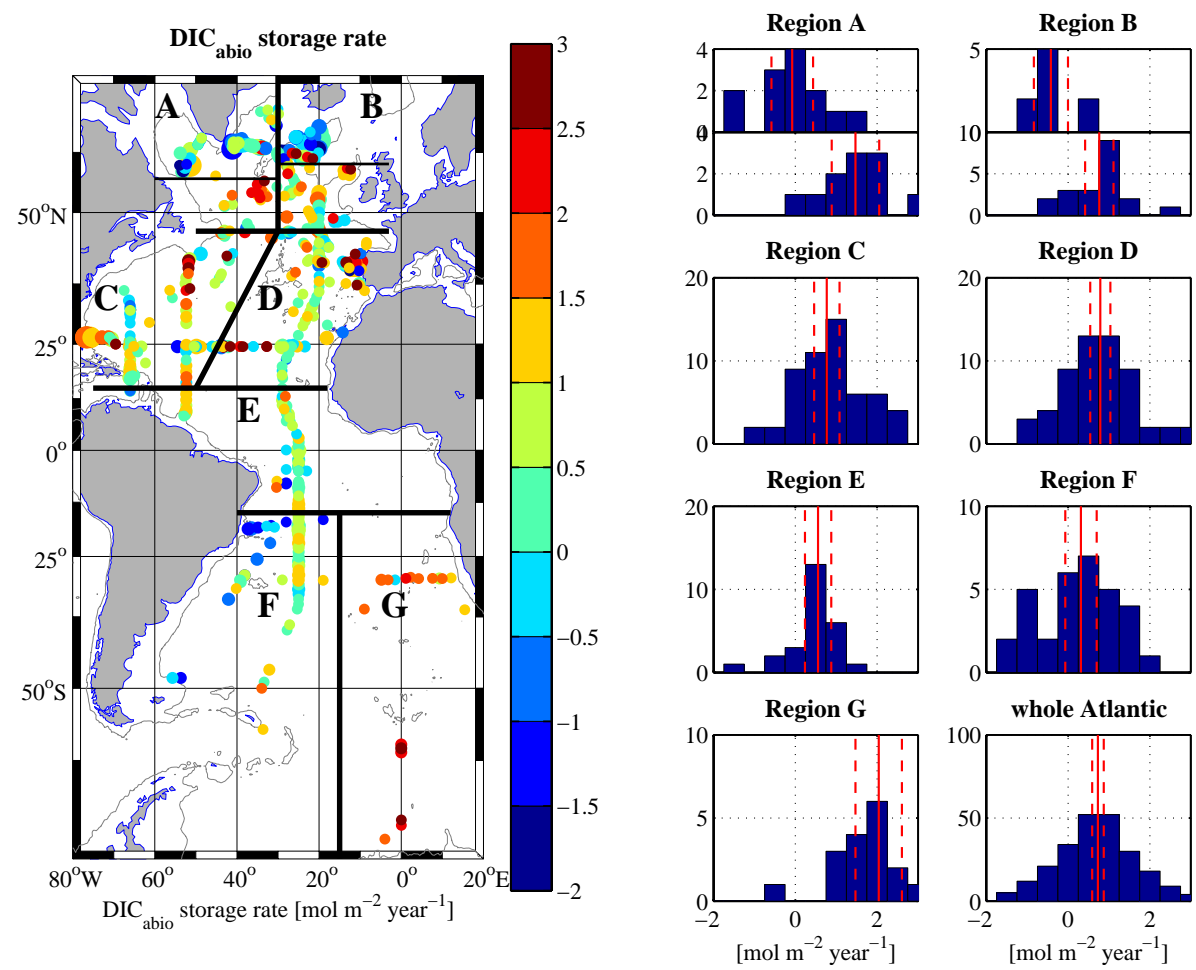

Fig. 3. Same as Fig. 2 but for storage rates $\left(\mathrm{mol} \mathrm{m}^{-2} \mathrm{yr}^{-1}\right)$ of $\mathrm{DIC}_{\mathrm{abio}}$.
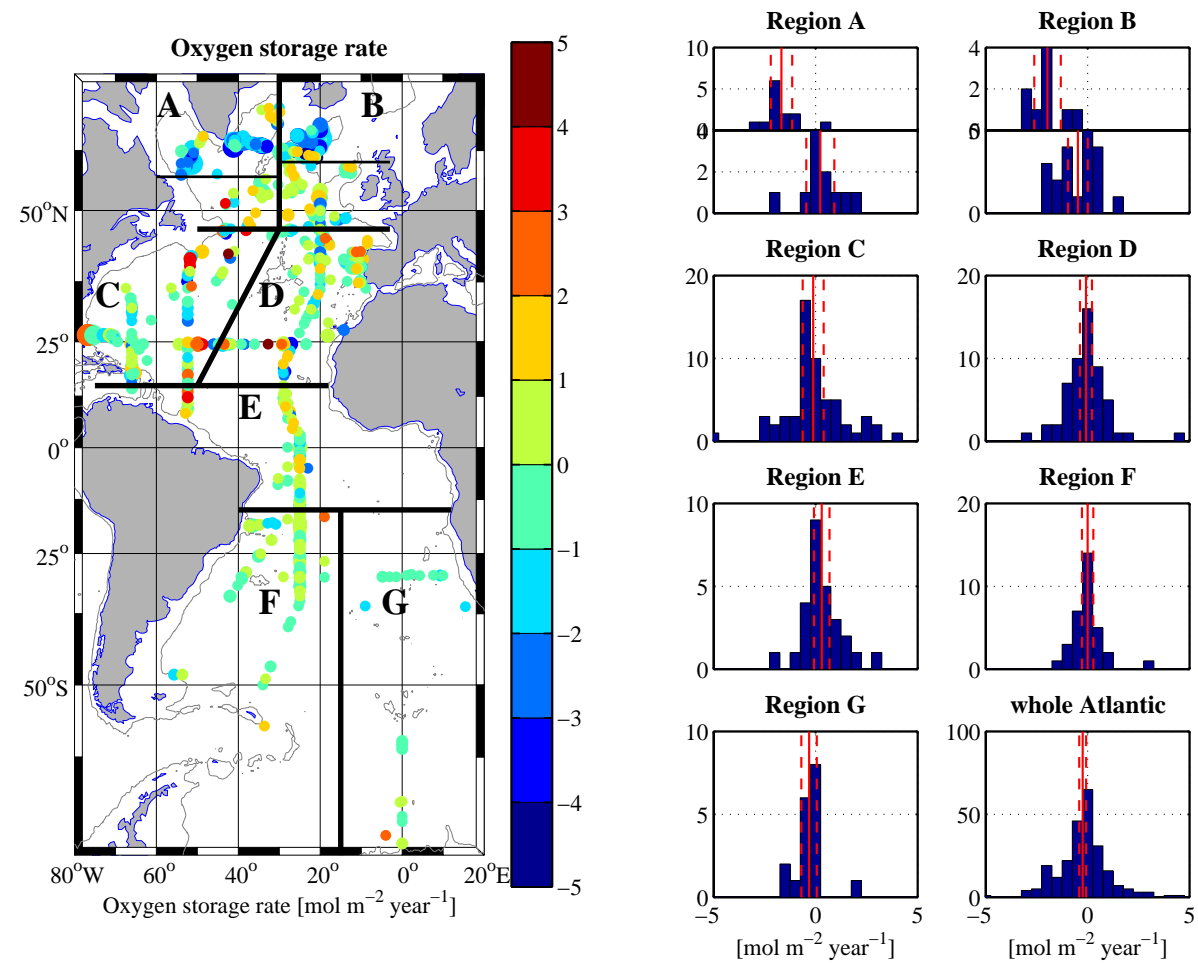

Fig. 4. Same as Fig. 2 but for storage rates $\left(\mathrm{mol} \mathrm{m}^{-2} \mathrm{yr}^{-1}\right)$ of oxygen. 


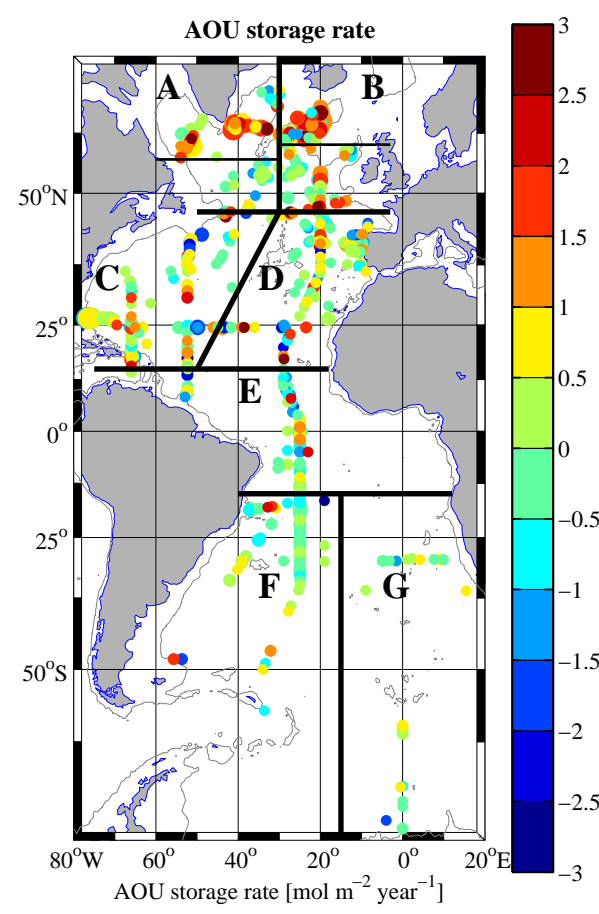

Fig. 5. Same as Fig. 2 but for storage rates $\left(\mathrm{mol} \mathrm{m}^{-2} \mathrm{yr}^{-1}\right)$ of AOU.

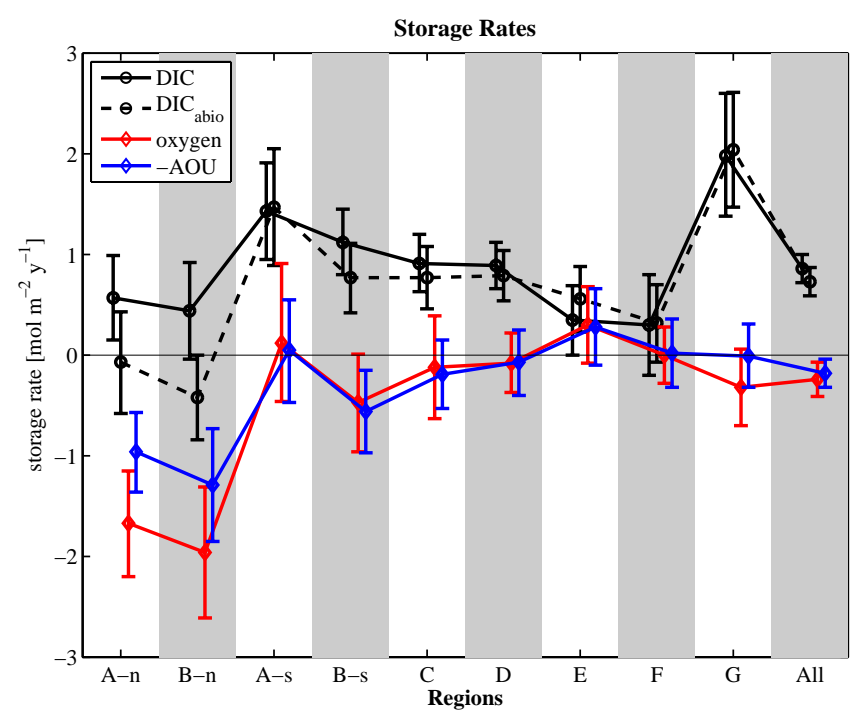

Fig. 6. Graphical representation of the storage rates for DIC, $\mathrm{DIC}_{\mathrm{abio}}$, oxygen and $\mathrm{AOU}$ for the 9 regions (regions $\mathrm{C}-\mathrm{G}$ and the northern and southern sub-regions for $\mathrm{A}$ and $\mathrm{B}$ ) as well as the whole Atlantic Ocean. The vertical error bars represent the $95 \%$ confidence interval of the data.

The averaged DIC and $\mathrm{DIC}_{\text {abio }}$ storage rates for the northern North Atlantic (regions A and B) are generally somewhat smaller (Table 1) than reported storage rates of anthropogenic carbon in this area (e.g. Sabine and Tanhua, 2010).
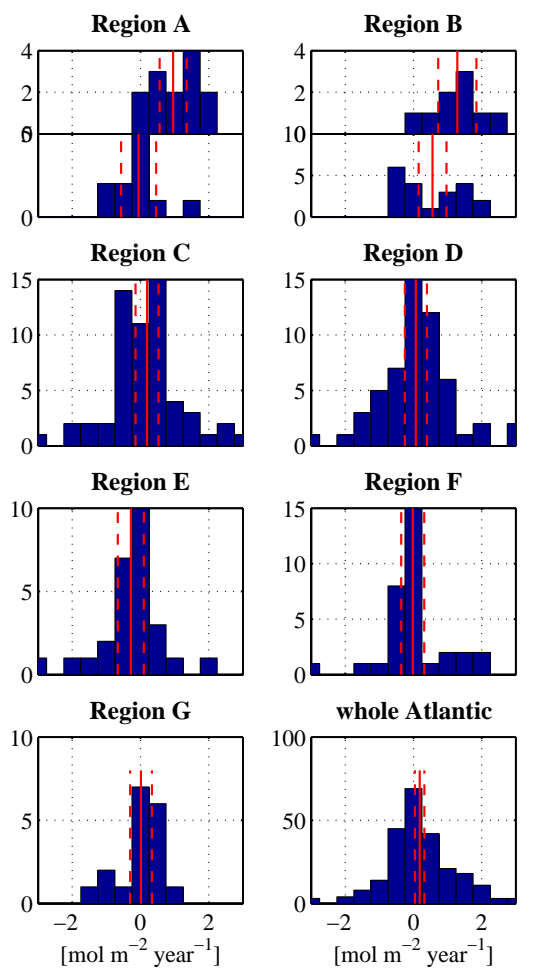

Perfect agreement is not expected, however, because other published methods tend to implicitly correct for changes DIC caused by biological activity and circulation in order to calculate the "anthropogenic carbon", see Sect. 4, below. Another obvious reason for these differences is that our method only evaluates the changes in the water column above $2000 \mathrm{~m}$ depth, whereas the published literature generally analyzes the whole water column. For the North Atlantic a significant amount of anthropogenic carbon has penetrated the water column deeper than $2000 \mathrm{~m}$ depth (e.g. Tanhua et al., 2007; Sabine and Tanhua, 2010; Pérez et al., 2010). This bias can probably be up to about $0.5 \mathrm{~mol} \mathrm{~m}^{-2} \mathrm{yr}^{-1}$, but must vary spatially depending on the presence of recently ventilated deep water. There are also significant differences in storage rates DIC and DIC $_{\text {abio }}$ between the northern and southern parts of regions A and B (Figs. 2 and 3); the storage rates are generally higher in the south and for stations pairs with a large time span (i.e. time between repeats). The $\mathrm{DIC}_{\mathrm{abio}}$ storage rates are lower than the DIC storage rates for regions $\mathrm{A}$ and B, see Sect. 3.

For the subtropical North Atlantic (regions C and D) we find DIC and $\mathrm{DIC}_{\mathrm{abio}}$ storage rates of about 0.9 and $0.8 \mathrm{~mol} \mathrm{~m}^{-2} \mathrm{yr}^{-1}$, respectively. This is comparable to, and within the uncertainty of, previously published results using various approaches to calculate the storage rates of $\mathrm{C}_{\mathrm{ant}}$ : in general, the eMLR based estimate by (Wanninkhof et al., 2010; Peng and Wanninkhof, 2010) are in the lower range of the storage rates in this study, whereas slightly higher storage 
rates are found by Tanhua et al. (2007), see also Sabine and Tanhua (2010). The tropical region (region E) has relatively low storage rates of DIC and $\mathrm{DIC}_{\text {abio }}$ (Table 1), in agreement with the low inventory of $C_{\text {ant }}$ (e.g. Lee et al., 2003) in the tropical Atlantic, although significant spatial variability has been noted for the tropical Atlantic (Schneider et al., 2012).

In the southwest Atlantic (region F) we find storage rates of $\mathrm{DIC}$ and $\mathrm{DIC}_{\mathrm{abio}}$ insignificantly larger than the "no change" condition, i.e. the storage rates are insignificantly different from zero, Table 1 . However, (Wanninkhof et al., 2010) found find high storage rates of $\mathrm{C}_{\mathrm{ant}}$ $\left(0.76 \mathrm{~mol} \mathrm{~m}^{-2} \mathrm{yr}^{-1}\right)$ in the Southwest Atlantic along the WOCE section A16, i.e. in region F. Similarly, Ríos et al. (2012) also finds high $\left(0.92 \pm 0.13 \mathrm{~mol} \mathrm{~m}^{-2} \mathrm{yr}^{-1}\right)$ storage rates of $\mathrm{C}_{\mathrm{ant}}$ for the southwest Atlantic Ocean. For the southeast Atlantic, region G in Fig. 1, we find the highest inventory rate of DIC and $\mathrm{DIC}_{\mathrm{abio}}$ of all our areas in the Atlantic (Table 1). This is in contrast to the results presented by Murata et al. (2008) who found an inventory rate of only $0.43-0.49 \mathrm{~mol} \mathrm{~m}^{-2} \mathrm{yr}^{-1}$, (although for $\mathrm{C}_{\mathrm{ant}}$ ) partly using the same data as in this study (i.e. the repeats of WOCE section A10 in 1993 and 2003). Note that the previously published results are assessing the change in $\mathrm{C}_{\mathrm{ant}}$, so that a difference can be expected.

The well-known pattern of $\mathrm{C}_{\mathrm{ant}}$ column inventory, i.e. high values in the subpolar North Atlantic (SPNA), low in the tropics and intermediate values in the subtropics of both hemispheres, are not well reflected in our maps of DIC and DIC $_{\text {abio }}$ storage rates (Figs. 2 and 3). Interestingly, we find relatively low $\mathrm{DIC}_{\text {abio }}$ storage rates in the subpolar North Atlantic, a region where large positive storage rates have been reported for $\mathrm{C}_{\mathrm{ant}}$ (e.g. Friis et al., 2005; Pérez et al., 2008, 2010). The difference between storage rates of

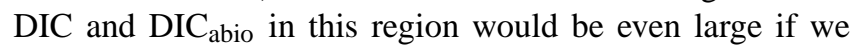
adopt the higher $\mathrm{C} /-\mathrm{O}_{2}$ ratio of Körtzinger et al. (2001), i.e. the $\mathrm{DIC}_{\mathrm{abio}}$ storage rate for region A-north would be $-0.15 \mathrm{~mol} \mathrm{~m}^{-2} \mathrm{yr}^{-1}$ rather than $-0.07 \mathrm{~mol} \mathrm{~m}^{-2} \mathrm{yr}^{-1}$. In this data set, there are signs of higher than average increase of DIC and $\mathrm{DIC}_{\mathrm{abio}}$ off the Iberian Peninsula, in the southeast Atlantic, off Florida and close to the Charlie-Gibbs Fracture Zone, and possibly in the northwest subtropical Atlantic.

\section{Oxygen and AOU storage rates}

For oxygen and AOU a somewhat different picture emerges (Figs. 4 and 5). For the Atlantic Ocean as a whole there is a negative storage rate of oxygen; the average of all our data is -0.24 (CI: $-0.41-(-0.07)) \mathrm{mol} \mathrm{m}^{-2} \mathrm{yr}^{-1}$, and a positive storage rate of AOU; 0.18 (CI: 0.004-0.32) $\mathrm{mol} \mathrm{m}^{-2} \mathrm{yr}^{-1}$. The storage rates of oxygen and AOU are significantly different from zero for regions A and B only, as well for the average over all regions. Particularly, significant decrease in oxygen (and increase in AOU) column inventories are observed in the Labrador Sea, the Irminger Sea and in the north- ern part of the Iceland Basin. The change in AOU, and the confidence interval of the change, is somewhat smaller than that for oxygen indicting that some of variability is tied to changes in solubility, mostly due to changes in temperature of the water. This solubility component of the $\mathrm{O}_{2}$ changes must be closely tied to the change in the inventory of heat. For instance, out-gassing of oxygen due to a warming ocean will not cause any direct changes in AOU, i.e. changes in AOU are indicative of air-sea $\mathrm{O}_{2}$ fluxes driven by biology or circulation. For the regions outside of SPNA, no significant change in the column inventory of oxygen or AOU can be detected with this method.

\subsection{Temporal variations}

In order to identify any temporal trends in storage rates, the data on storage rates for three different time periods are evaluated. Station pairs where both repeats are conducted in the any of the time-periods 1980-1995, 1990-2000, or 1995-2005 were identified. This required discarding additional pairs done more than 15 (or 10) yr apart, which further increases the uncertainty of the storage rates for each area (i.e. decreases the number of available samples). Since the resulting coverage is very sparse in most regions, we focus on the two northernmost regions (A - the western part of the SPNA, and B - the eastern portion of the SPNA) where more data is available, and where significant changes in deep water formation has occurred over time (e.g. Rhein et al., 2011). The data for the 3 time periods are displayed in Figs. 7 to 10

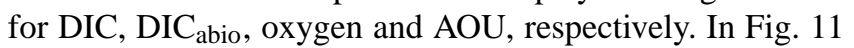
the information for regions $\mathrm{A}$ and $\mathrm{B}$ is condensed.

It can be noted that, as expected, significant spatial variations are present, even within each region, but that some interesting patterns can be recognized. For the first time slice (1980-1995) an increase in oxygen, DIC and DIC abio $_{\text {can be }}$ observed for both regions (i.e. positive storage rates), particular for region B, although only a limited number of station pairs are available to confirm this trend. During the1990s the conditions are significantly different with negative storage rates of oxygen and close to neutral storage rates of DIC. During the last time slice (1995-2005) again a different picture emerges with different patterns for the western and the eastern domain. For region A, the storage rate for oxygen is continuously negative whereas the DIC positive; region B show positive storage rates of DIC but neutral oxygen storage rates. It is clear that there are both temporal and spatial variability in the storage rates of DIC and oxygen in the North Atlantic subpolar gyre, particularly for the northern part of the region.

\section{Discussion}

Based on estimates of the total storage of anthropogenic carbon in the world ocean, the globally averaged storage rate for 


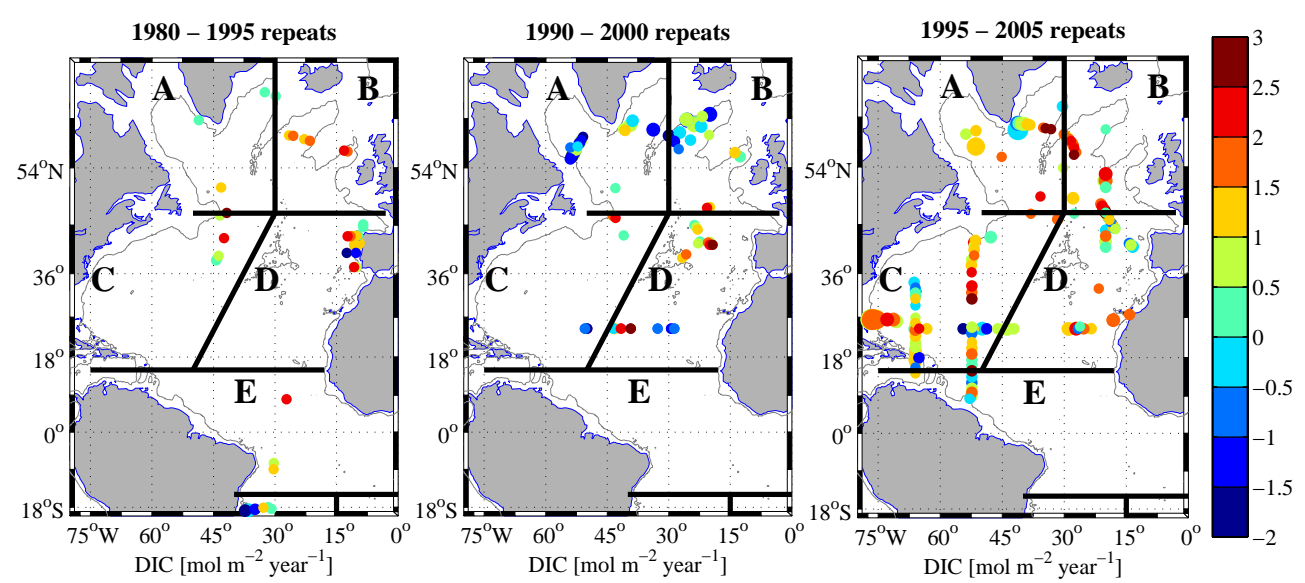

Fig. 7. Storage rates for DIC for three different time periods. Left panel - storage rates for repeats where both cruises were conducted between 1980 and 1995; middle panel - both repeats were conducted between 1990 and 2000; right panel - both repeats were conducted between 1995 and 2005. The $2000 \mathrm{~m}$ isobath is marked with a gray thin line.

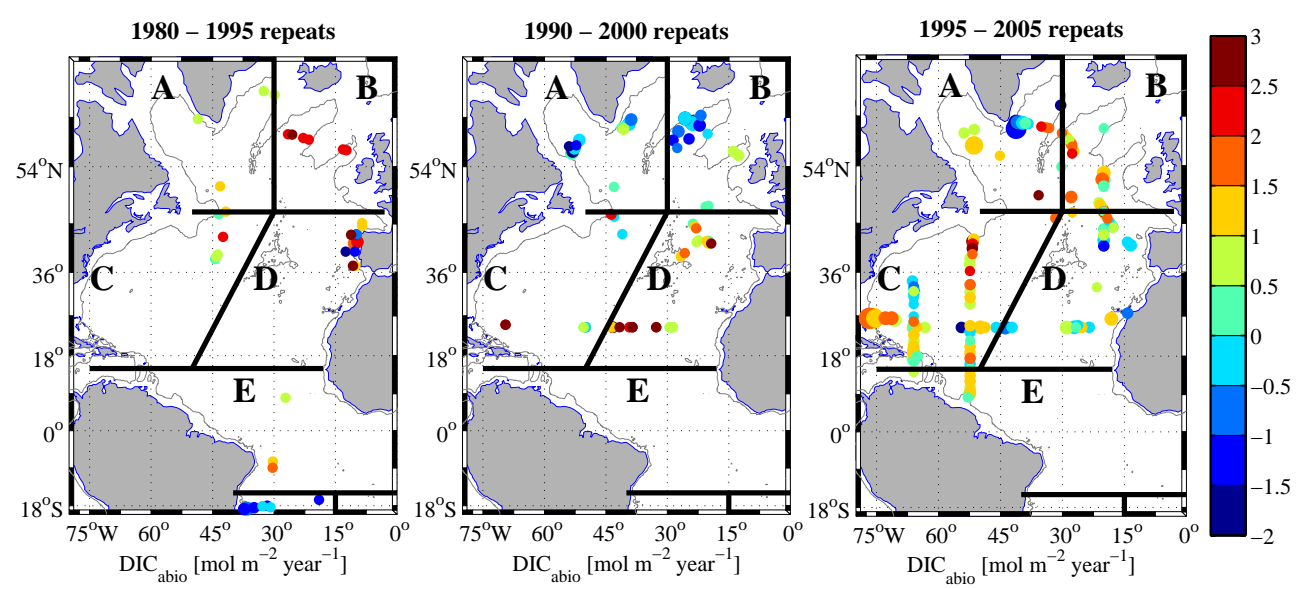

Fig. 8. Same as Fig. 7 but for storage rates $\left(\mathrm{mol} \mathrm{m}^{-2} \mathrm{a}^{-1}\right)$ of $\mathrm{DIC}_{\text {abio }}$.

$\mathrm{C}_{\text {ant }}$ has been increasing from roughly $0.2 \mathrm{~mol} \mathrm{~m}^{-2} \mathrm{yr}^{-1}$ in 1960 to $0.6 \mathrm{~mol} \mathrm{~m}^{-2} \mathrm{yr}^{-1}$ in 2007 (Khatiwala et al., 2009). The storage rate is expected to show significant regional variability assuming that the regional pattern of storage rate is similar to that of the total storage, see for instance the Atlantic Ocean map of $\mathrm{C}_{\text {ant }}$ column inventory in Lee et al. (2003). However, there are a few important differences between this study and the calculation by Lee et al. (2003). Most importantly this study reports on the change in DIC and DIC $_{\text {abio }}$ which is not equal to the change in $C_{a n t}$ so that temporal changes in the storage rate of DIC which is not evident by observing the total storage of $\mathrm{C}_{\text {ant }}$ becomes relevant. Changes in $\mathrm{DIC}_{\mathrm{abio}}$ should be largely conserved in the ocean interior as it compensates for respiration, but could change in surface water due to either air-sea exchange of $\mathrm{CO}_{2}$ or $\mathrm{O}_{2}$. Changes in column inventory of $\mathrm{DIC}_{\mathrm{abio}}$ will therefore largely reflect a combination of the effects of long-term $\mathrm{CO}_{2}$ and $\mathrm{O}_{2}$ exchange with the atmosphere, with the $\mathrm{CO}_{2}$ effect presumably dominating as a result of the uptake of anthro- pogenic $\mathrm{CO}_{2}$. The regional patterns of storage rate of DIC and $\mathrm{DIC}_{\text {abio }}$ in this analysis is significantly different than the well-known distribution of column inventory of $\mathrm{C}_{\mathrm{ant}}$ in the Atlantic Ocean. In general, a mixed pattern of positive and negative storage rates are found in each region. The picture generally gets somewhat less patchy when considering only shorter time-periods, Figs. 6-9. Since this method of calculating storage rates does not account for small-scale temporal and spatial variability due to, for instance eddies and movements of oceanic fronts, larger variability in the storage rate is expected than from methods that do compensate for this, such as MLR based approaches. The larger scatter also reflect the additional difficulties in determining inventory changes for the total amount of DIC rather than the anthropogenic perturbation $\left(\mathrm{C}_{\mathrm{ant}}\right)$, see discussion below.

It is interesting to compare our result with the results presented by Steinfedt et al. (2009) who observed only a weak increase in the $\mathrm{C}_{\mathrm{ant}}$ column inventory (2\%) in the Labrador Sea and Irminger Sea during the 1997-2003 time period 


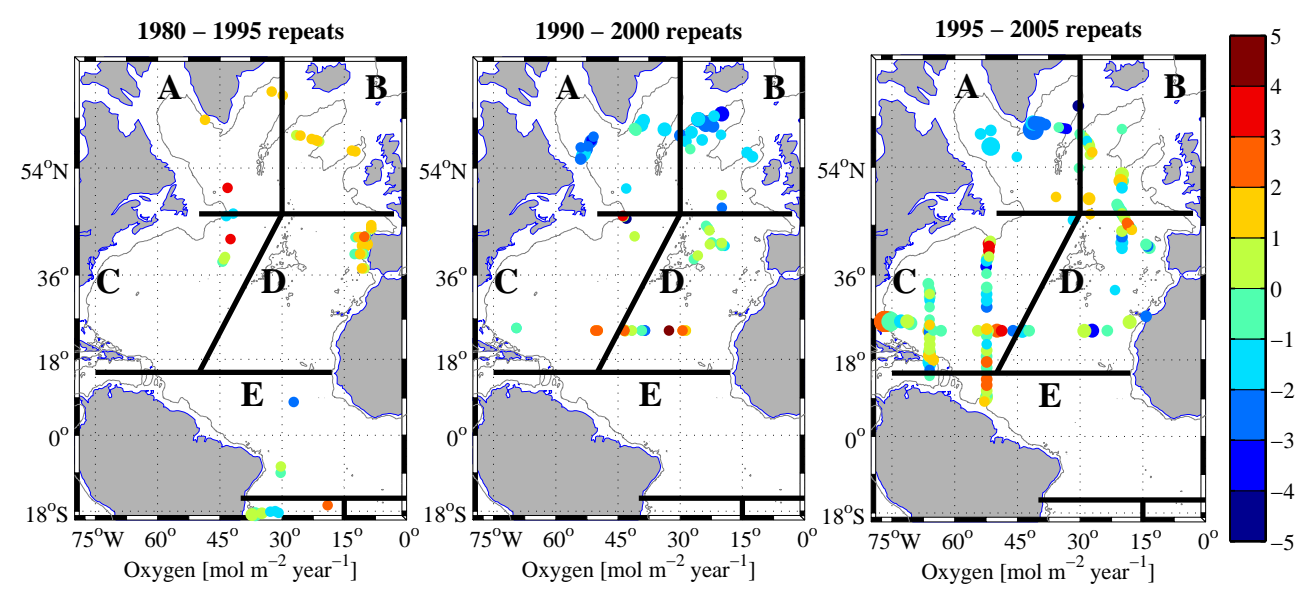

Fig. 9. Same as Fig. 7 but for storage rates $\left(\mathrm{mol} \mathrm{m}^{-2} \mathrm{a}^{-1}\right)$ of oxygen.

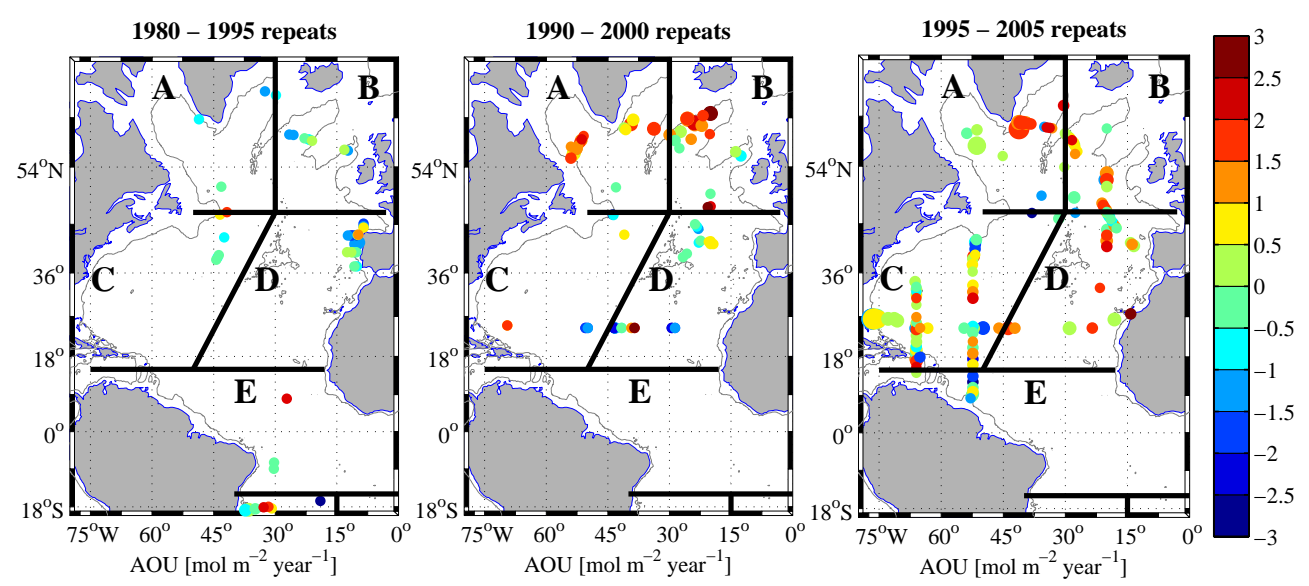

Fig. 10. Same as Fig. 7 but for storage rates $\left(\mathrm{mol} \mathrm{m}^{-2} \mathrm{a}^{-1}\right)$ of AOU.

based on transient tracer observations. This is roughly the same time period (1995-2005) for which we find a significant increase in the column inventory of DIC and DIC $a$ bio storage rates in the same region. A water mass analysis suggest that the volume of the classic Labrador Sea Water (LSW) decreased due to decreasing deep water formation in the Labrador Sea, and as a consequence there is an increase of a lighter (i.e. less dense) version of the LSW (e.g. Rhein et al., 2011; Steinfeldt et al., 2009). Thus the deep version of the LSW only experience limited ventilation during this time, i.e. the LSW is getting "older". This provides an explanation to the observation that the column inventory of $\mathrm{C}_{\mathrm{ant}}$ remains close to constant (restricted communication with the increasing atmospheric $\mathrm{CO}_{2}$ concentrations) and why the DIC is increasing (remineralization of organic matter) more than $\mathrm{DIC}_{\mathrm{abio}}$ and oxygen concentrations decreases during this time period. This analysis thus confirms the conclusion by Steinfeldt et al. (2009) that the northwest subpolar gyre of the Atlantic Ocean is a region that shows significant devia- tion from the expected average uptake rate of anthropogenic carbon.

Our analysis can also be compared with Pérez et al. (2008), who studied a time series of biogeochemistry data in the southern Irminger Sea, i.e. the northern part of region A. They note a trend of increasing AOU for the LSW, starting in the mid-1990s, which is similar to the observations in this study (Fig. 10). By using a data-based back-calculation method to infer the $C_{\text {ant }}$ concentration, they conclude that there is a significantly positive storage rate of $\mathrm{C}_{\mathrm{ant}}$ for the time period 1981 to $2006\left(1.1 \pm 0.1 \mathrm{~mol} \mathrm{~m}^{-2} \mathrm{yr}^{-1}\right)$, and a particularly large storage rate during the time period 1991$1997\left(2.3 \pm 0.6 \mathrm{~mol} \mathrm{~m}^{-2} \mathrm{yr}^{-1}\right)$. The trends in $\mathrm{C}_{\text {ant }}$ concentration for the water masses in the SPNA is also discussed in detail by Pérez et al. (2010), where they divide the region into three areas, as opposed to the two (four) areas in this study. They found positive storage rates for $\mathrm{C}_{\text {ant }}$ for the time period 1981 to 2006 for the whole SPNA. Similar to the study from 2008 (Pérez et al., 2008) for the Irminger Sea, they also find large differences in storage rates with time, and 


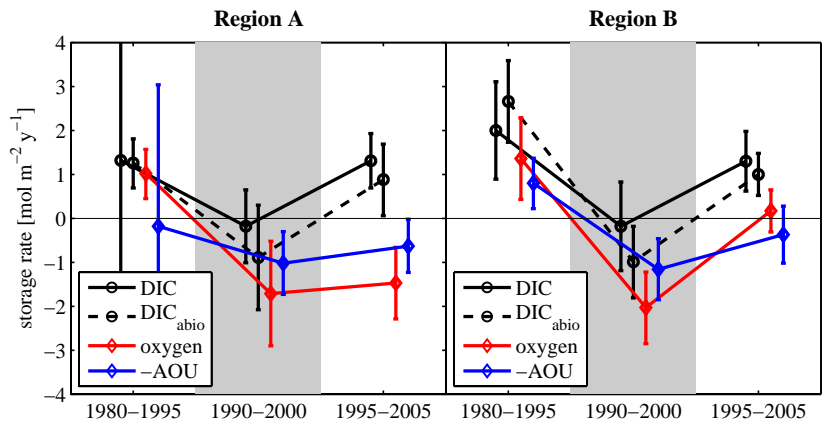

Fig. 11. Storage rates for DIC, DIC $\mathrm{abio}, \mathrm{AOU}$ and oxygen for regions A and B for three time periods (1980-1995, 1990-2000, and 1995-2005), see Figs. 6-9. Note that negative AOU is plotted and that the markers are slightly offset for clarity. The error-bars the $95 \%$ confidence interval of the variation of storage rates within each area calculated from the values of the $2^{\circ} \times 2^{\circ}$ bins (see text).

correlate this to the North Atlantic Oscillation (NAO) and the formation rate of Labrador Sea Water. They find particularly high storage rates during the period 1991 to 1998 (i.e. during the time of intense formation of LSW) for the Irminger Sea and the Iceland Basin, whereas the East North Atlantic Basin seem to have a more linear increase of storage rate for $\mathrm{C}_{\mathrm{ant}}$ $\left(0.77 \pm 0.03 \mathrm{~mol} \mathrm{~m}^{-2} \mathrm{yr}^{-1}\right)$ (Pérez et al., 2008, 2010). This overlaps with the time period (1990-2000) where we find slightly negative storage rates for DIC and $\mathrm{DIC}_{\mathrm{abio}}$. However, since the analysis in this study is only covering the upper $2000 \mathrm{~m}$ of the water column, storage changes in the deeper part of the water column remains unaccounted for. For this region, with active deep water formation and significant advection of overflow water, the deeper parts might indeed be important and is a source of error in this comparison. Significant temporal variations in $T, S$ and dissolved $\mathrm{O}_{2}$ occurred in the SPNA during the last $\sim 60 \mathrm{yr}$ are also reported by van Aken et al. (2011) who conclude that the long-term variations of the intermediate water mass properties in the SPNA are related to meteorological forcing of the Labrador Sea. Significant changes in the SPNA salinity balance has been observed during the last half century (Curry and Mauritzen, 2005) which can be consistent with varying dominance of different water masses. Based on this analysis it seems that these long-term variations also affect the inventory of DIC in the SPNA.

The storage rates of DIC and DICabio in the southern parts of regions A and B are significantly higher than for the northern parts, and conform better to published estimates of $\mathrm{C}_{\mathrm{ant}}$ in the region. For instance, a recent study by McGrath et al. (2012) found storage rates of $C_{a n t}$ in the Rockall Trough of $1.2 \mathrm{~mol} \mathrm{~m}^{-2} \mathrm{a}^{-1}$ for the layer between 200 and $2000 \mathrm{~m}$. The oxygen and AOU storage rates are close to neutral in the southern parts of regions A and B, i.e. similar to other areas further south in the Atlantic.
A detailed study of the temporal evolution of the inorganic carbon content in the SPNA is out of scope for this study. It is, however, interesting to point out the diverging trends of $\mathrm{C}_{\mathrm{ant}}$ and DIC found in this region may relate to varying convection activity and water mass distribution. It seems that the inventory of DIC decreases at the same time as the inventory of $\mathrm{C}_{\mathrm{ant}}$ increases. An explanation for this can be provided by changes in water mass distribution in the SPNA. For instance, the DIC concentration of LSW is in the order of $2160 \mu \mathrm{mol} \mathrm{kg}-1$, whereas the DIC concentration of the Mediterranean Sea Overflow Water (in the Gulf of Cadiz) is in the order of $2200 \mu \mathrm{mol} \mathrm{kg}{ }^{-1}$, even though both water masses have relatively high, and somewhat similar concentration of $\mathrm{C}_{\mathrm{ant}}$. These two water masses are both present in the SPNA and variability in the relative presence of these two water masses will change the column inventory of DIC in a way that is not necessarily reflected in storage of $\mathrm{C}_{\mathrm{ant}}$.

Recently, Stendardo and Gruber (2012) used a long-term data set for dissolved oxygen in the North Atlantic Ocean to assess any trends over the past $49 \mathrm{yr}$. She finds a complex pattern of temporal changes in oxygen concentrations; the upper water masses have generally lost oxygen, particularly in the eastern and northern Atlantic, whereas deeper layers have generally gained oxygen, particularly in the southwestern part of the North Atlantic. The results are based on observed changes in oxygen concentration for different density intervals (i.e. water masses). In a more detailed study focusing of repeats of the $\mathrm{A} 2$ sections (i.e. a zonal section across the Atlantic Ocean at $\sim 47^{\circ} \mathrm{N}$ ), Stendardo (2011) concludes that the oxygen concentrations show strong inter-annual variability with a tendency towards oxygen loss over time. The results presented in this study are, in general, supporting the results of Stendardo (2011) with particularly large losses of oxygen in the northern part of the North Atlantic. However, the results are difficult to compare direct as this study is focusing on the changes in column inventory rather than the concentration in various water masses.

\section{Concluding remarks}

A simple method associated with few assumptions to constrain the ocean storage rate of dissolved inorganic carbon (DIC), respiration corrected DIC (DIC $\mathrm{Dabio})$, oxygen, and apparent oxygen utilization (AOU) has been demonstrated. By calculating the difference in the column inventory of these properties down to $2000 \mathrm{~m}$ depth over the whole Atlantic Ocean for a large number of repeat stations we find generally find increase in DIC and a decrease of oxygen. The trends reported in this analysis supports other studies that have reported on increasing concentrations of inorganic carbon in the ocean based on more complicated schemes, and providing some support for the general trend of ocean deoxygenation. The degree of uncertainty in calculating trends in interior ocean properties with this method demonstrates the importance of small scale spatial and temporal variability 
in the ocean. One important aspect of this analysis is that variations in water mass prevalence have a large influence on inventories of interior ocean properties so that the total DIC inventory can decrease in an area even if the inventory of $\mathrm{C}_{\mathrm{ant}}$ significantly increases. This has implications for balancing the global carbon budget that do not distinguish between "anthropogenic carbon" and "natural carbon". From a global perspective it is the overall increasing or decreasing inventory of carbon in the ocean that matters to balance the budget.

Acknowledgements. The research leading to these results was supported through EU FP7 project CARBOCHANGE "Changes in carbon uptake and emissions by oceans in a changing climate" which received funding from the European Community's Seventh Framework Programme under grant agreement no. 264879. We thank Mark Lenz for useful discussions on statistics. This work was carried out in part while RFK was on sabbatical leave at the Leibniz Institute of Marine Sciences in Kiel, supported by the Humboldt Foundation and the Cluster of Excellence "FutureOcean".

Edited by: F. Joos

\section{References}

Anderson, L. A. and Sarmiento, J. L.: Redfield ratios of remineralization determined by nutrient data analysis, Global Biogeochem. Cy., 8, 65-80, 1994.

Cermeno, P., Dutkiewicz, S., Harris, R. P., Follows, M., Schofield, O., and Falkowski, P. G.: The role of nutricline depth in regulating the ocean carbon cycle, P. Natl. Acad. Sci. USA, 105, 2034420349, doi:10.1073/pnas.0811302106, 2008.

Curry, R. and Mauritzen, C.: Dilution of the Northern North Atlantic Ocean in Recent Decades, Science, 308, 1772-1774, doi:10.1126/science.1109477, 2005.

Friis, K., Körtzinger, A., Pätsch, J., and Wallace, D. W. R.: On the temporal increase of anthropogenic $\mathrm{CO}_{2}$ in the subpolar North Atlantic, Deep-Sea Res. Part I, 52, 681-698, doi:10.1016/j.dsr.2004.11.017, 2005.

Gammon, R. H., Cline, J., and Wisegarver, D. P.: Chluorofluoromethanes in the Northeast Pacific Ocean: Measured Vertical Distribution and Application as Transient Tracers of Upper Ocean Mixing, J. Geophys. Res., 87, 9441-9454, 1982.

Helm, K. P., Bindoff, N. L., and Church, J. A.: Observed decreases in oxygen content of the global ocean, Geophys. Res. Lett., 38, L23602, doi:10.1029/2011g1049513, 2011.

Keeling, R. F.: Comment on "The Ocean Sink for Anthropogenic $\mathrm{CO}_{2}$ ", Science, 308, 1743c, 2005.

Keeling, R. F. and Garcia, H. E.: The change in oceanic O-2 inventory associated with recent global warming, P. Natl. Acad. Sci. USA, 99, 7848-7853, 2002.

Keeling, R. F., Körtzinger, A., and Gruber, N.: Ocean Deoxygenation in a Warming World, Annual Review of Marine Science, 2, 199-229, doi:10.1146/annurev.marine.010908.163855, 2010.

Key, R. M., Kozyr, A., Sabine, C. L., Lee, K., Wanninkhof, R., Bullister, J. L., Feely, R. A., Millero, F. J., Mordy, C., and Peng, T. H.: A global ocean carbon climatology: Results from Global
Data Analysis Project (GLODAP), Global Biogeochem. Cy., 18, GB4031, doi:1029/2004GB002247, 2004.

Key, R. M., Tanhua, T., Olsen, A., Hoppema, M., Jutterström, S., Schirnick, C., van Heuven, S., Kozyr, A., Lin, X., Velo, A., Wallace, D. W. R., and Mintrop, L.: The CARINA data synthesis project: introduction and overview, Earth Syst. Sci. Data, 2, 105121, doi:10.5194/essd-2-105-2010, 2010.

Khatiwala, S., Primeau, F., and Hall, T.: Reconstruction of the history of anthropogenic $\mathrm{CO}_{2}$ concentrations in the ocean, Nature, 462, 346-349, doi:10.1038/nature08526, 2009.

Körtzinger, A., Hedges, J. I., and Quay, P. D.: Redfield ratios revisited: Removing the biasing effect of anthropogenic $\mathrm{CO}_{2}$, Limnol. Oceanogr., 46, 964-970, 2001.

Lee, K., Choi, S.-D., Park, G.-H., Wanninkhof, R., Peng, T. H., Key, R. M., Sabine, C. L., Feely, R. A., Bullister, J. L., Millero, F. J., and Kozyr, A.: An updated anthropogenic $\mathrm{CO}_{2}$ inventory in the Atlantic Ocean, Global Biogeochem. Cy., 17, 1116, doi:10.1029/2003GB002067, 2003.

Levine, N. M., Doney, S. C., Wanninkhof, R., Lindsay, K., and Fung, I. Y.: Impact of ocean carbon system variability on the detection of temporal increases in anthropogenic $\mathrm{CO}_{2}$, J. Geophys. Res., 113, C03019, doi:10.1029/2007JC004153, 2008.

Levitus, S., Antonov, J. I., Boyer, T. P., Baranova, O. K., Garcia, H. E., Locarnini, R. A., Mishonov, A. V., Reagan, J. R., Seidov, D., Yarosh, E. S., and Zweng, M. M.: World ocean heat content and thermosteric sea level change (0-2000 m), 1955-2010, Geophys. Res. Lett., 39, L10603, doi:10.1029/2012g1051106, 2012.

McGrath, T., Kivimäe, C., Tanhua, T., Cave, R. R., and McGovern, E.: Inorganic carbon and $\mathrm{pH}$ levels in the Rockall Trough 1991-2010, Deep-Sea Res. Part I, 68, 79-91, doi:10.1016/j.dsr.2012.05.011, 2012.

Murata, A., Kumamoto, Y., Sasaki, K., Watanabe, S., and Fukasawa, M.: Decadal increases of anthropogenic $\mathrm{CO}_{2}$ in the subtropical South Atlantic Ocean along 30 degrees S, J. Geophys. Res., 113, C06007, doi:10.1029/2007JC004424, 2008.

Peng, T.-H. and Wanninkhof, R.: Increase in anthropogenic $\mathrm{CO}_{2}$ in the Atlantic Ocean in the last two decades, Deep-Sea Res. Part I, 57, 755-770, doi:10.1016/j.dsr.2010.03.008, 2010.

Pérez, F. F., Vázquez-Rodríguez, M., Louarn, E., Padín, X. A., Mercier, H., and Ríos, A. F.: Temporal variability of the anthropogenic $\mathrm{CO}_{2}$ storage in the Irminger Sea, Biogeosciences, 5, 1669-1679, doi:10.5194/bg-5-1669-2008, 2008.

Pérez, F. F., Vázquez-Rodríguez, M., Mercier, H., Velo, A., Lherminier, P., and Ríos, A. F.: Trends of anthropogenic $\mathrm{CO}_{2}$ storage in North Atlantic water masses, Biogeosciences, 7, 1789-1807, doi:10.5194/bg-7-1789-2010, 2010.

Pierrot, D., Brown, P., Van Heuven, S., Tanhua, T., Schuster, U., Wanninkhof, R., and Key, R. M.: CARINA $\mathrm{TCO}_{2}$ data in the Atlantic Ocean, Earth Syst. Sci. Data, 2, 177-187, doi:10.5194/essd-2-177-2010, 2010.

Rhein, M., Kieke, D., Hüttl-Kabus, S., Roessler, A., Mertens, C., Meissner, R., Klein, B., Böning, C. W., and Yashayaev, I.: Deep water formation, the subpolar gyre, and the meridional overturning circulation in the subpolar North Atlantic, Deep-Sea Res. Part II, 58, 1819-1832, doi:10.1016/j.dsr2.2010.10.061, 2011.

Riebesell, U., Schulz, K. G., Bellerby, R. G. J., Botros, M., Fritsche, P., Meyerhofer, M., Neill, C., Nondal, G., Oschlies, A., Wohlers, J., and Zollner, E.: Enhanced biological carbon consumption in a high $\mathrm{CO}_{2}$ ocean, Nature, 450, 545-548, 
doi:10.1038/nature06267, 2007.

Ríos, A. F., Velo, A., Pardo, P. C., Hoppema, M., and Pérez, F. F.: An update of anthropogenic $\mathrm{CO}_{2}$ storage rates in the western South Atlantic basin and the role of Antarctic Bottom Water, J. Mar. Systems, 94, 197-203, doi:10.1016/j.jmarsys.2011.11.023, 2012.

Sabine, C. L. and Tanhua, T.: Estimation of Anthropogenic $\mathrm{CO}_{2}$ Inventories in the Ocean, Annual Reviews of Marine Sciences, 2, 175-198, doi:10.1146/annurev-marine-120308-080947, 2010.

Sabine, C. L., Key, R. M., Johnson, K. M., Millero, F. J., Poisson, A., Sarmiento, J. L., Wallace, D. W. R., and Winn, C. D.: Anthropogenic $\mathrm{CO}_{2}$ inventory of the Indian Ocean, Global Biogeochem. Cy., 13, 179-198, 1999.

Sabine, C. L., Key, R. M., Kozyr, A., Feely, R. A., Wanninkhof, R., Millero, F., Peng, T. H., Bullister, J., and Lee, K.: Global Ocean data analysis project (GLODAP): Results and data, ORNL/CDIAC-145, NDP-083, 2005.

Schneider, A., Tanhua, T., Körtzinger, A., and Wallace, D. W. R.: An evaluation of tracer fields and anthropogenic carbon in the equatorial and the tropical North Atlantic, DeepSea Res. Part I: Oceanographic Research Papers, 67, 85-97, doi:10.1016/j.dsr.2012.05.007, 2012.

Steinfeldt, R., Rhein, M., Bullister, J. L., and Tanhua, T.: Inventory changes in anthropogenic carbon from 1997-2003 in the Atlantic Ocean between 20 degrees S and 65 degrees N, Global Biogeochem. Cy., 23, GB3010, doi:10.1029/2008GB003311, 2009.

Stendardo, I.: Interannual to decadal variability and trends of the oceanic oxygen content in the North Atlantic, $\mathrm{PhD}$, Institute of Biogeochemistry and Pollutant Dynamics, ETH, Zürich, 185 pp., 2011.

Stendardo, I., and Gruber, N.: Oxygen trends over five decades in the North Atlantic, J. Geophys. Res., 117, C11004, doi:10.1029/2012jc007909, 2012.

Stendardo, I., Gruber, N., and Körtzinger, A.: CARINA oxygen data in the Atlantic Ocean, Earth Syst. Sci. Data, 1, 87-100, doi:10.5194/essd-1-87-2009, 2009.

Tanhua, T. and Wallace, D. W. R.: Consistency of TTO-NAS Inorganic Carbon Data with modern measurements, Geophys. Res. Lett., 32, L14618, doi:10.1029/2005GL023248, 2005.
Tanhua, T., Körtzinger, A., Friis, K., Waugh, D. W., and Wallace, D. W. R.: An estimate of anthropogenic $\mathrm{CO}_{2}$ inventory from decadal changes in ocean carbon content, P. Natl. Acad. Sci. USA., 104, 3037-3042, doi:10.1073/pnas.0606574104, 2007.

Tanhua, T., van Heuven, S., Key, R. M., Velo, A., Olsen, A., and Schirnick, C.: Quality control procedures and methods of the CARINA database, Earth Syst. Sci. Data, 2, 35-49, doi:10.5194/essd-2-35-2010, 2010.

Touratier, F. and Goyet, C.: Decadal evolution of anthropogenic $\mathrm{CO}_{2}$ in the northwestern Mediterranean Sea from the mid1990s to the mid-2000s, Deep-Sea Res. Part I, 56, 1708-1716, doi:10.1016/j.dsr.2009.05.015, 2009.

Touratier, F., Azouzi, L., and Goyet, C.: CFC-11, Delta C-14 and H3 tracers as a means to assess anthropogenic $\mathrm{CO}_{2}$ concentrations in the ocean, Tellus B, 59, 318-325, 2007.

van Aken, H. M., Femke de Jong, M., and Yashayaev, I.: Decadal and multi-decadal variability of Labrador Sea Water in the northwestern North Atlantic Ocean derived from tracer distributions: Heat budget, ventilation, and advection, Deep-Sea Res. Part I, 58, 505-523, doi:10.1016/j.dsr.2011.02.008, 2011.

Velo, A., Perez, F. F., Brown, P., Tanhua, T., Schuster, U., and Key, R. M.: CARINA alkalinity data in the Atlantic Ocean, Earth Syst. Sci. Data, 1, 45-61, doi:10.5194/essd-1-45-2009, 2009.

Wakita, M., Watanabe, S., Murata, A., Tsurushima, N., and Honda, M.: Decadal change of dissolved inorganic carbon in the subarctic western North Pacific Ocean, Tellus B, 62, 608-620, doi:10.1111/j.1600-0889.2010.00476.x, 2010.

Wanninkhof, R., Doney, S. C., Bullister, J. L., Levine, N. M., Warner, M., and Gruber, N.: Detecting anthropogenic $\mathrm{CO}_{2}$ changes in the interior Atlantic Ocean between 1989 and 2005, J. Geophys. Res., 115, C11028, doi:10.1029/2010JC006251, 2010.

Weiss, R.: Solubility of Nitrogen, Oxygen and Argon in water and seawater, Deep-Sea Res., 17, 721-735, 1970.

Yool, A., Oschlies, A., Nurser, A. J. G., and Gruber, N.: A modelbased assessment of the TrOCA approach for estimating anthropogenic carbon in the ocean, Biogeosciences, 7, 723-751, doi:10.5194/bg-7-723-2010, 2010. 